\title{
Oxidase-like Function by Apo-Transferrin towards Manganese(III) Chelates
}

\author{
Takahiro Satoh ${ }^{1}$, Keita $_{\text {Abe }}{ }^{1} \&$ Yuzo Nishida ${ }^{1}$ \\ ${ }^{1}$ Medical Research Institute, Kanazawa Medical University, Uchinada-machi 1-1, Japan \\ Correspondence: Yuzo Nishida, Medical Research Institute, Kanazawa Medical University, Uchinada-machi 1-1, \\ Kahoku-gun, Ishikawa Prefecture 920-0293, Japan. Tel: 81-76-225-8406. E-mail: \\ nsd-2210@kanazawa-med.ac.jp
}

Received: February 29, 2012 Accepted: March 12, 2012 Online Published: May 27, 2012

doi:10.5539/ijc.v4n3p10 URL: http://dx.doi.org/10.5539/ijc.v4n3p10

\begin{abstract}
We have observed that oxidation of $\mathrm{Mn}$ (III) ion in several manganese chelates to a $\mathrm{Mn}$ (IV) state occurs in the presence of apo-transferrin, and at the same time facile up-take of manganese ion by apo-transferrin proceeds. This clearly shows that much manganese ions can be transported to the brain by transferrin under the certain conditions, which may lead to manganism. Based on these results we have prepared the new chelate to capture only the $\mathrm{Mn}(\mathrm{III})$ and $\mathrm{Mn}(\mathrm{IV})$ ions selectively, but not $\mathrm{Mn}(\mathrm{II})$ ion, and to remove these manganese ions from the solution without toxicity.
\end{abstract}

Keywords: oxidation of $\mathrm{Mn}(\mathrm{III})$ ion, Apo-transferrin, oxidase-like function, manganism, chelation therapy

\section{Introduction}

Elevated occupational exposures to manganese are known to cause significant neurotoxicity, and epidemiologic studies have suggested that a relationship between elevated manganese exposure and an increased risk for parkinsonian disturbances, called manganism, although the exact mechanisms underlying the neurotoxic effects of manganese remain unclear (Dobson et al., 2004; Choi et al., 2010). It has been reported that rats exposed to very elevated manganese levels via drinking water from an early age displayed increased brain manganese levels and altered copper and iron levels in the striatum and in the basal ganglia. Transport of manganese ions into the central nervous system has been directly investigated in a limited number of studies, and it has become that the likeliest modes of transport are by transferrin/transferrin receptor and DMT-1 (Dobson et al., 2004). It is generally believed that iron and manganese ions are able to be complexed and carried by transferrin/transferrin receptor, with iron being far more prevalent under normal circumstances. Several authors strongly suggest transport of trivalent manganese complexed to transferrin into the brain capillary endothelium, although the exact mechanisms underlying the transport of manganese into the brain by transferrin remain unclear (Heilig et al., 2006).

In our previous study we investigated the manganese ion uptake by apo-transferrin in terms of the capillary electrophoresis method (Abe et al., 2008), and obtained the clear evidence that oxidation state, +3 and binuclear unit of a manganese chelate are critical factors for the facile uptake by apo-transferrin, similar to that observed for Fe(III) species (Nishida et al., 2007). In this study we observed that facile oxidation of Mn(III) ion in several manganese chelates to a Mn(IV) state occurs in the reaction mixture containing apo-transferrin. The significance of this oxidase-like function of apo-transferrin will be developed in this study.

\section{Experimental}

\subsection{Reagents}

Apo-transferrin (bovine: T1428-100MG) and holo-transferrin (bovine: T1283-100MG) were purchased form Sigma. Manganese compounds were prepared according to the published methods (Sutoh et al., 2005; Okuno et al., 1996), $\mathrm{Mn}^{\mathrm{II}}($ dpea $) \mathrm{Cl}_{2}, \quad \mathrm{Mn}^{\mathrm{II}}(\mathrm{dpa}) \mathrm{ClClO}_{4}, \quad \mathrm{Mn}^{\mathrm{II}}(\mathrm{dpal}) \mathrm{Cl}_{2}, \quad \mathrm{Mn}^{\mathrm{III} / \mathrm{V}}{ }_{2} \mathrm{O}_{2}(\mathrm{dpa})_{2}\left(\mathrm{ClO}_{4}\right), \mathrm{Mn}^{\mathrm{III} / \mathrm{IV}}{ }_{2} \mathrm{O}_{2}(\mathrm{Me}-\mathrm{en}-\mathrm{py})_{2}$ $\left(\mathrm{ClO}_{4}\right)_{3}$, the chemical structures of the ligands being illustrated in Figure 1. New binuclear pinkish-brown manganese(III) complex, $\mathrm{Mn}_{2}{ }_{2}(\mathrm{Me}-\mathrm{en}-\mathrm{py})_{2}(\mathrm{O})\left(\mathrm{CH}_{3} \mathrm{COO}\right)\left(\mathrm{PF}_{6}\right)_{2}$ was prepared in this study from the reaction mixture containing the ligand (Me-en-py), manganese(III) acetate, and $\mathrm{NH}_{4} \mathrm{PF}_{6}$. Analytical data and magnetic property $\left(\mu_{\text {eff }}=5.04(295 \mathrm{~K})\right.$ and $=5.06(81.4 \mathrm{~K})$ are consistent with the assumed structure of the binuclear manganese(III) complex with $\mu$-oxo and $\mu$-acetate bridge (Nishida et al., 1997). The (dpea), (dpa), (dpal) and 
(Me-en-py) represent N,N-bis(2-pyridylmethyl)ethanolamine, N,N-bis(2-pyridylmethyl)glycine, N,N-bis(2pyridylmethyl)- $\beta$-alanine, and N,N'-bis(2-pyridylmethyl)-N,N'-dimethyl-ethylenediamine, respectively.

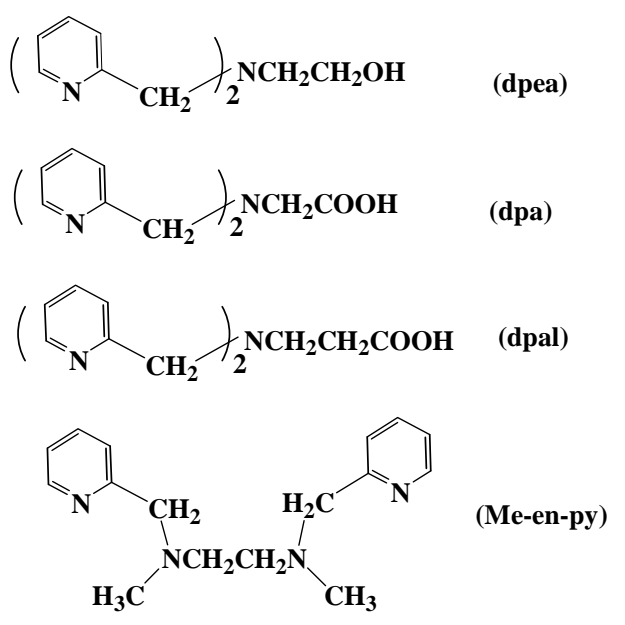

Figure 1. Chemical structures of ligands cited in this paper

\subsection{Measurements}

All the manganese chelate solutions used in this study were prepared by dissolving the crystalline manganese compounds in tris-buffer solution $(10 \mathrm{mM}, \mathrm{pH} 7.3)$. ESR spectra of the solution containing a manganese chelate in buffer solution $(10 \mathrm{mM}, \mathrm{pH} 7.3)$ are obtained with a JEOL ESR Apparatus mode RE-2X at $77 \mathrm{~K}$. Two solutions in tris-buffer solution $(\mathrm{pH}=7.3,10 \mathrm{mM})$ containing apo-transferrin $(2 \mathrm{mg} / 1 \mathrm{ml})$ and manganese complex $(5 \mathrm{mM})$ were mixed.

\section{Results and Discussion}

\subsection{Oxidase-like Function of Apo-transferrin}

All the manganese(II) complex solutions used in this study are colorless. The colorless Mn(II)(dpea) in the buffer solution became pale-brown when the solution was kept stand for more than one day, demonstrating that $\mathrm{Mn}(\mathrm{II})$ ion in the $\mathrm{Mn}$ (II)(dpea) chelate is readily oxidized to a $\mathrm{Mn}$ (III) ion in the atmosphere (Abe et al., 2008). The oxidation to a Mn(III) species does not proceed in the compounds with (dpa), (dpal) and (Me-en-py) under the same conditions. The addition of colorless apo-transferrin to the aged pale-brown $\mathrm{Mn}(\mathrm{dpea})$ complex solution immediately induced the color change to dark-brown, and in our previous paper we have concluded that the dark-brown solution derived from apo-transferrin and the aged pale-brown Mn-dpea solution should be due to the formation of $\mathrm{Mn}$ (III)-phenolate bonding in Mn(III)-transferrin (Abe et al., 2008).

In order to obtain the more information of the above process, we have measured the ESR spectra of the solutions. No ESR signal was observed for the pale-brown solution of $\mathrm{Mn}(\mathrm{II})(\mathrm{dpea})$ complex (see Figure 2-(A)), which is consistent with the general concept that almost all the Mn(III) species are ESR-non-detectable (Abragam \& Bleaney, 1970). On the other hand, we have found 16 lines in the ESR spectrum of the dark-brown solution, as illustrated in Figure 2-(B). The same 16-line ESR signals was also observed in the solution containing apo-transferrin and the binuclear $\mathrm{Mn}(\mathrm{III})$ complex with (Me-en-py), $\mathrm{Mn}^{\mathrm{III}}{ }_{2}(\mathrm{Me}-\mathrm{en}-\mathrm{py})_{2}(\mathrm{O})\left(\mathrm{CH}_{3} \mathrm{COO}\right)\left(\mathrm{PF}_{6}\right)_{2}$. These are clearly implying that in the solution containing apo-transferrim, the $\mathrm{Mn}(\mathrm{III})$ ion of the several chelates is readily oxidized to a Mn(IV) state, forming a binuclear $\mathrm{Mn}(\mathrm{III}) / \mathrm{Mn}(\mathrm{IV})$ species with di- $\mu$-oxo bridge, because it has been pointed out that 16-line ESR signal observed in the figure is diagnostic for the binuclear $\mathrm{Mn}(\mathrm{III}) / \mathrm{Mn}(\mathrm{IV})$ species with di- $\mu$-oxo bridge (Okuno \& Nishida, 1996). Thus it seems very rational to assume that formation of a Mn(IV) species in the solution plays a key step for the transport of a manganese ion to apo-transferrin, which should be supported by the fact that facile transport of manganese ion was observed in the solution containing apo-transferrin and a binuclear $\mathrm{Mn}(\mathrm{III}) / \mathrm{Mn}(\mathrm{IV})$ complex with di- $\mu$-oxo-bridge (Abe et al., 2008).

As stated in Introduction (Dobson et al., 2004), it is generally believed that iron and manganese ions are able to be complexed and carried by transferrin/transferrin receptor, with iron being far more prevalent under normal circumstances. But, this is only true under the circumstance that the manganese ion exists as a manganese(II) ion, 
i.e., the prevalency of the iron ion over the manganese ion is not valid when the $\mathrm{Mn}(\mathrm{III})$ and $\mathrm{Mn}(\mathrm{IV})$ ions are present in the plasma, and such condition may be induced by the normal conditions as described in this paper. Thus the present results may give important information to understand the mechanism of the manganese ion transport to the brain, which should induce manganism.

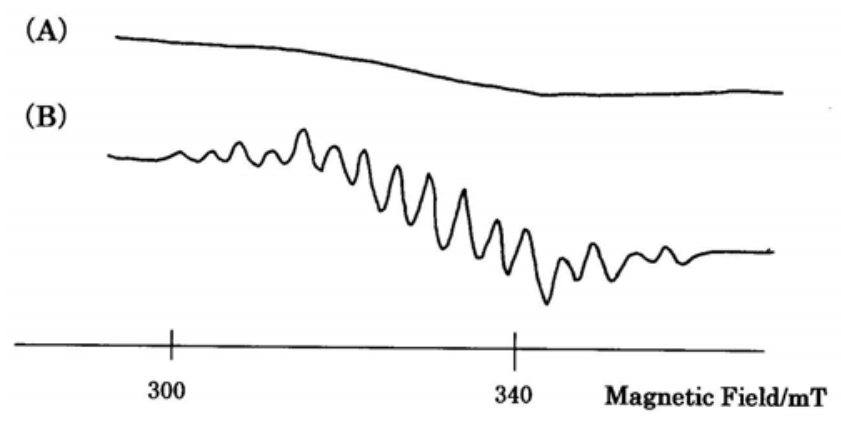

Figure 2. ESR spectra of (A) pale-brown solution of Mn(II)(dpea) complex, and (B) apo-transferrin was added to the solution $(\mathrm{A})$

The oxidase-like function of apo-transferrin observed in this study suggests that the ferroxidase function by apo-transferrin may occur in the solution containing iron(II) ions. Thus, the present observation should be very important to elucidate the origin of the excessive neurovisceral accumulation of iron detected in the brains of aceruloplasminemia patients (Yoshida et al., 2000).

\subsection{Manganism and Prion Disease}

Recent studies on mice experimentally infected with scrapie suggested that large increase in the levels of manganese ion occurs in blood and brain prior to the onset of symptoms of the prion disease; at the same time the elevated manganese ion in several central nervous systems and the increase of labile plasma iron in certain regions of the brain were observed (Brown, 2009). It is quite likely that much hydrogen peroxide is produced by the misfolded $\mathrm{Cu}-\mathrm{PrP}^{\mathrm{Sc}}$ protein through its SOD-like function in the mice infected with scrapie (Nishida, 2011a), and this hydrogen peroxide may induce the increasing of the labile manganese ion which contain manganese ions with high oxidation states, $\mathrm{Mn}(\mathrm{III})$ and $\mathrm{Mn}(\mathrm{IV})$, in the blood as described in our previous paper (Abe et al., 2008). Excess accumulation of manganese ion in the brain induces the abnormality in the synthesis of several neurotransmitters, and the abnormality in the iron metabolism, leading to the increase of the labile plasma iron which gives a serious damage to the proteins, DNA, and other important substances (Nishida, 2004, 2011a; Hider et al., 2008). Thus, it is reasonable to conclude that the prion diseases including both the sporadic and infected types should be elucidated by the combined toxicity due to the labile plasma manganese and iron ions.

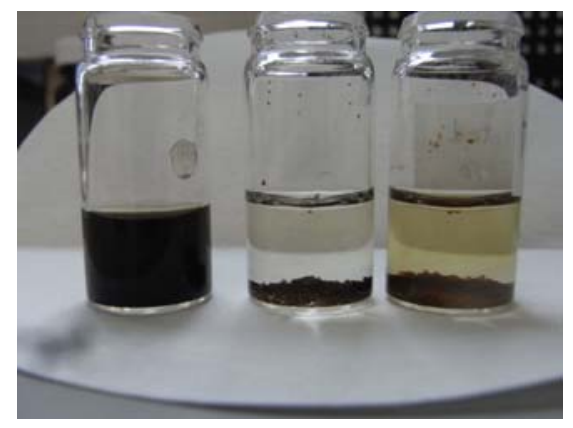

Figure 3. Left; the solution of $\mathrm{Mn}^{\mathrm{III} / \mathrm{V}}{ }_{2} \mathrm{O}_{2}(\mathrm{dpa})_{2}\left(\mathrm{ClO}_{4}\right)(1 \mathrm{mmol})$. Right, at 5 minutes after addition of the new chelate $(10 \mathrm{mg})$ to the solution. Middle, at 30 minutes after the addition. The solution became completely clear with the formation of brown deposits

Above discussions clearly demonstrate that the delete of the labile plasma manganese and iron ions should be one of the best ways to prevent the prion diseases and other neurodegenerative disorders. Very recently we have 
synthesized the special chelates which capture labile plasma iron ions and exclude them from the solution without toxicity (Nishida, 2011b), and found that one of these chelates can capture only the Mn(III) and Mn(IV) ions selectively, but not $\mathrm{Mn}(\mathrm{II})$ ion (Brazier et al., 2010), and remove these manganese ions from the solution without toxicity (see Figure 3). We hope that our new chelates should make notable contribution to the prevention and therapeutics for the manganism, prion disease, schizophrenia, and dementia, etc.

\section{Conclusion}

We have observed that oxidase-like function by the apo-transferrin operates in the solution containing a Mn(III) chelate, and it seems quite likely that this activity by apo-transferrin may occur in the presence of a $\mathrm{Fe}(\mathrm{II})$ compound. Thus, our observation should be very important to elucidate the origin of the excessive neurovisceral accumulation of iron detected in the brains of aceruloplasminemia patients.

\section{References}

Abe, K., Chiba, Y., \& Nishida, Y. (2008). Facile uptake of manganese(III) by apotransferrin:Possible origin of manganesim. Z. Naturforsch., 63c, 154-156.

Abragam, A., \& Bleaney, B. (1970). Electron Paramagnetic Resonance of Transition Ions. London: Clarendon Press.

Brazier, M. W., Volitakis, V., Kvasnicka, M., White, A. R., Underwood, J. R., Green, J. E., Han, S., Hill, A. F., Masters, C. L., \& Collins, S. J. (2010). Manganese chelation therapy extends survival in a mouse model of M1000 prion disease. J. Neurochem., 114, 440-450. http://dx.doi.org/10.1111/j.1471-4159.2010.06771.x

Brown, D. (2009). Brain proteins that mind metals: a neurodegenerative perspective. Dalton Trans., 21, 4069-4076. http://dx.doi.org/10.1039/b822135a

Choi, C. J., Anantharam, V., Martin, D., Nicholson, E. M., Richt, J. A., Kanthasamy, A., \& Kanthasamy, A. G. (2010). Manganese upregulates cellur prion protein and contributes to altered stabilization and proteolysis: Relevance to role of metals in pathogenesis of prion disease. Toxicol. Sciences, 115, 535-546. http://dx.doi.org/10.1093/toxsci/kfq049

Dobson, A. W., Erikson, K. M., \& Asachner, M. (2004). Manganese neurotoxicity. Ann. New York Acad. Sci., 1012, 115-128. http://dx.doi.org/10.1196/annals.1306.009

Heilig, E. A., Thonpson, K. J., Molina, R. M., Ivanov, A. R., Brain, J. D., \& W.-Resnick, M. (2006). Manganese and iron transport across pulmonary epithelium. Am. J. Physiol. Lung Cell Mol. Physiol., 290, L1247-L1259. http://dx.doi.org/10.1152/ajplung.00450.2005

Hider, R. C., Ma, Y., Molina-Holgato, F., Gaeta, A., \& Roy, S. (2008). Iron chelation as a potential therapy for neurodegenerative disease. Biochem Soc Trans, 36, 1304-1308. http://dx.doi.org/10.1042/BST0361304

Nishida, Y., Ito, Y., \& Satoh, T. (2007). Origin of renal proximal tubular injuries by Fe(III)-nta chelate. Z. Naturforsch., 62c, 608-612.

Nishida, Y., Nasu, M., \& Tokii, T. (1990). Variety of oxidation state of manganese ions in compounds with tripod-like ligands. Z. Naturforsch., 45b, 1093-1095.

Nishida, Y. (2004). Oxidative stress and neurodegeneration, Med Hypothesis Res., 1, 227-245.

Nishida, Y. (2009). Structural characteristics of iron(III) chelates to induce tissue damage and renal carcinoma Chemical origin of the iron toxicity. TCIMail, 141, 2-15. Retrieved from http://www.tciamerica.com/tcilail/backnumber/article/141drE.pdf

Nishida, Y. (2011a). The chemical process of oxidative stress by copper(II) and iron(III) ions in several neurodegenerative disorders. Monatsh. Chem., 142, 375-384. http://dx.doi.org/10.1007/s00706-010-0444-8

Nishida, Y. (2011b). Japanese patent application: 2011-006043.

Okuno, T., \& Nishida, Y. (1996). Electron delocalization in binuclear manganese(III/IV) complexes with di- $\mu$-oxo bridges. Polyhedron, 15, 1509-1515. http://dx.doi.org/10.1016/0277-5387(95)00393-2

Sutoh, Y., Nishino, S., \& Nishida, Y. (2005). Metal chelates to prevent or clear the deposits of amyloid $\beta$-peptide(1-40) induced by zinc(II) chloride. Chem. Lett., 34, 140-141. http://dx.doi.org/10.1246/cl.2005.140

Yoshida, K., Kaneko, K., Miyajima, H., Tokuda, T., Nakamura, A., Kato, M., \& Ikeda, S. (2000). Increased lipid peroxidation in the brains of aceruloplasminemia patients. J. Neurological Sci., 175, 91-95. http://dx.doi.org/10.1016/S0022-510X(00)00295-1 